\title{
Development of a Building Automation Laboratory
}

\author{
William J. Hutzel \\ Purdue University, West Lafayette
}

\begin{abstract}
The Applied Energy Laboratory within the School of Technology at Purdue University is an instructional facility for heating, ventilating, and air conditioning equipment. The equipment for indoor climate control includes a forced air system, a hydronic (water-based) system, heat pumps, and solar collectors. All components are linked to an environmental chamber so that the performance of each type of equipment can be evaluated. To keep pace with state of the art industry practice, new equipment and software for direct digital control (DDC) of various laboratory components was recently installed. The new equipment is particularly useful because it has a graphical user interface for easier component visualization by inexperienced technicians, namely undergraduate students.
\end{abstract}

\section{Energy Conservation and Its Impact on Technical Careers}

The annual energy consumption in the United States will reach a whopping $8.0 \times 10^{16}$ Btu's in 1997. To put this enormous quantity in perspective, momentarily assume that this energy came from a coal pile the size of a football field. The imaginary coal pile would be roughly 300 miles high from end zone to end zone! Energy for indoor climate control is a large factor, accounting for almost $40 \%$ of this staggering total. In terms of the football field example, the annual energy used for heating, cooling, lighting, and appliances is equivalent to a coal pile over 100 miles high. Although the availability of coal and other fossil fuels is gradually decreasing, U.S. energy consumption is steadily increasing. ${ }^{2}$ It is not surprising that new technologies for efficiently managing energy use, particularly energy used for indoor climate control, are becoming extremely important.

The growing importance of energy conservation is reflected by several new career opportunities for Technologists and Engineers. Maintenance engineering, which involves operating and maintaining mechanical equipment for climate control of modern commercial buildings, is becoming an important career option. The Office of Manpower Studies within the School of Technology at Purdue University currently projects that Maintenance Engineering will be one of the fastest growing technical careers over the next decade. ${ }^{3}$ Career opportunities with energybased consulting firms have also become much more common. Energy consultants frequently perform facility-wide energy audits on schools, hospitals, and other large institutions to pinpoint opportunities for cost savings. Many renovation projects for new boilers, chillers, and other equipment are financed based on projected energy savings. Both maintenance engineers and energy consultants recognize the strong financial incentives for adopting new technologies that maximize a building's energy efficiency. 
One key area of expertise for maintenance engineers or energy consultants is Heating, Ventilating, and Air Conditioning (HVAC) . Like most technical fields, HVAC equipment has become increasingly automated. Great improvements in both indoor comfort and energy efficiency have been achieved by linking computers with heating and cooling equipment. Computer controls help maintain indoor temperature and humidity at comfortable levels regardless of outdoor fluctuations. More importantly, computers optimize energy efficiency by turning off equipment when it is not needed. Sophisticated features, such as automated fire suppression and building security, are frequently integral parts of this same computer package. Despite the importance and widespread use of these "building automation" systems by maintenance engineers or energy consultants, until recently the School of Technology at Purdue University lacked significant expertise in this important area of specialization.

\section{Building Automation in the Applied Energy Laboratory}

The Applied Energy Laboratory is located in the Knoy Hall of Technology on the Purdue University campus in West Lafayette, Indiana. The front room is a $1450 \mathrm{ft}^{2}$ student laboratory for thermodynamics and heat transfer. The back room is smaller, approximately $650 \mathrm{ft}^{2}$, and contains a variety of heating, ventilating, and air conditioning equipment. Figure 1 identifies the layout of the HVAC facility, which was the focal point of this building automation project. A laboratory scale forced air system and a hydronic (fluid-based) system are examples of equipment found in commercial HVAC installations. These components are linked to an environmental chamber so that their performance can be precisely evaluated. A water source heat pump, an air source heat pump, and an active solar collector loop demonstrate residential HVAC equipment.

To keep pace with state of the art industry practice, work is underway to implement building automation hardware and software for computer control of equipment in the Applied Energy Laboratory. Particular emphasis is being given to control systems that include a graphic user interface, which makes data interpretation easier for student researchers. The Department of Mechanical Engineering Technology has already made significant progress on this project. More than $\$ 10,000$ has been allocated in the past year to modernize the laboratory's HVAC equipment. The School's contribution was leveraged against a $\$ 24,000$ donation of building automation hardware and software from Automated Logic Corporation (ALC) of Kennesaw, Georgia. The remainder of this paper describes the building automation work that has been completed to date. 


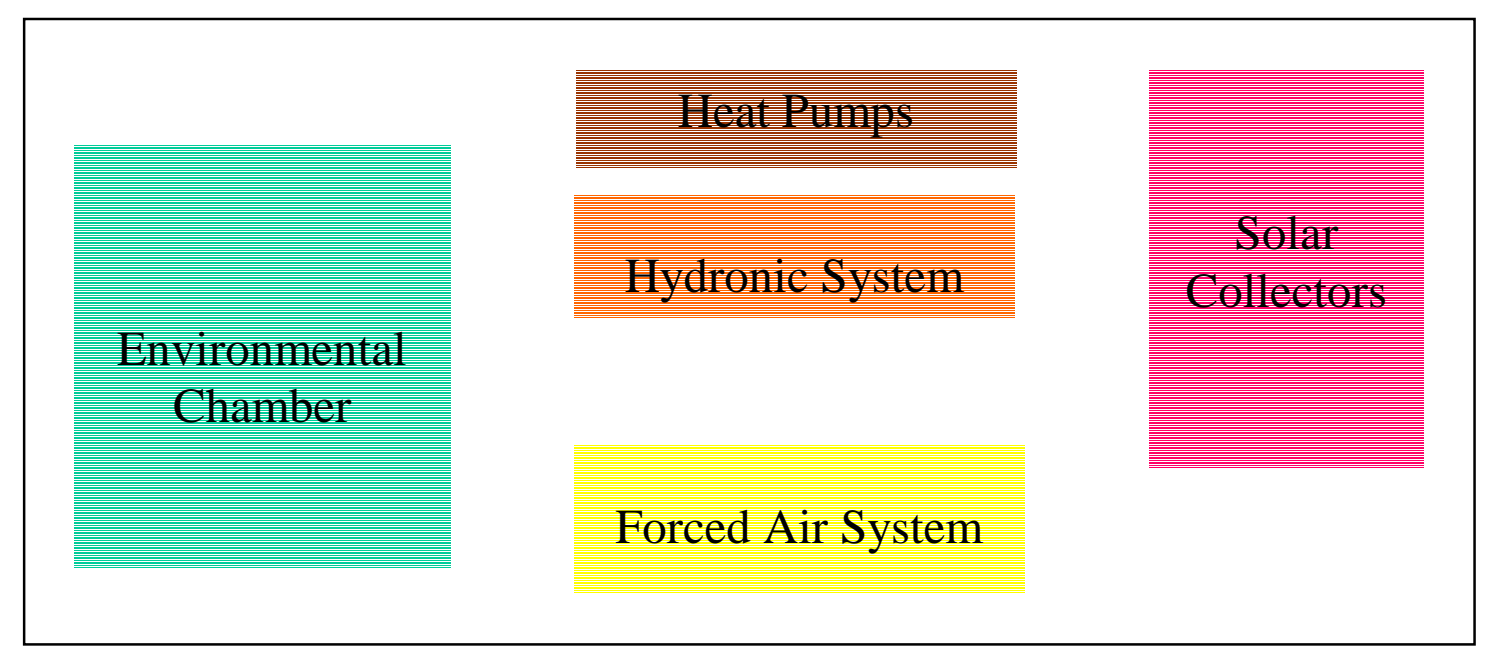

Figure 1. The Applied Energy Laboratory has a variety of HVAC equipment

\section{Renovation of the Forced Air System}

Figure 2 is a schematic of the forced air system in the Applied Energy Laboratory. Outside air is delivered to the air handler through an insulated duct. Before entering the air handler, outdoor air and recirculated air are mixed. Three dampers on the inlet, exhaust, and recirculation ducts control the relative amounts of outdoor and recirculated air. The combined air flow (outdoor + recirculated) is drawn over a cooling coil and a heating coil by a variable speed fan. Depending upon the relative humidity, the air can be humidified before being delivered to the environmental chamber. The environmental chamber mimics an actual building environment by creating heating and cooling loads that are independent of the forced air system.

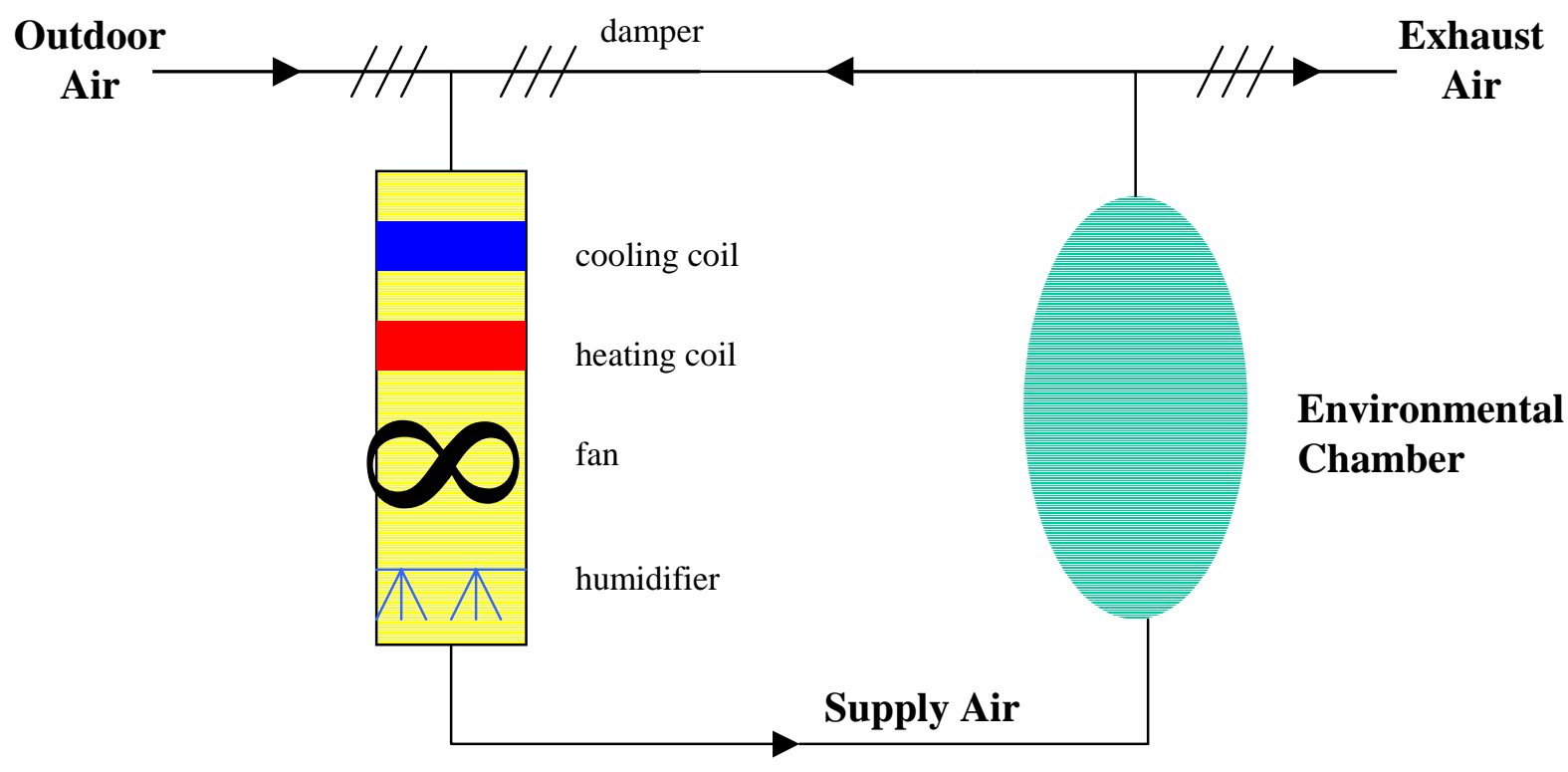

Figure 2. The forced air system delivers conditioned air to the environmental chamber. 
Although the mechanical equipment for the forced air system described above was fully operational for nearly 20 years, precise control of the system was extremely difficult. Most of the control components dated to the 1970's, well before computer controls were a reality. As a result, the forced air system behaved erratically. Undesirable temperature and humidity fluctuations in the environmental chamber made it difficult to demonstrate control concepts to Mechanical Engineering Technology students.

Renovation of the forced air system involved stripping away all of the original control components and replacing them with computer controls. For example, a series of nine old mechanical switches that sequenced nine independent elements of the heating coil were completely removed. In their place, a single 0-10Vcontrol signal from the Automated Logic controller now determines the power supplied by the heating coil. All of the original sensors for monitoring temperature, humidity, and static pressure were also removed and replaced. In some cases the difference between old and new sensor technology was striking. The original humidity controller was a mechanical switch whose sensing element was human hair, its replacement is a printed circuit board with a disk-shaped resistive sensing element. All the new sensors communicate directly with the Automated Logic controller. Figure 3 is a photograph of the refurbished forced air system. Most of the sensors are installed behind the two stainless steel panels in the middle of the photograph.

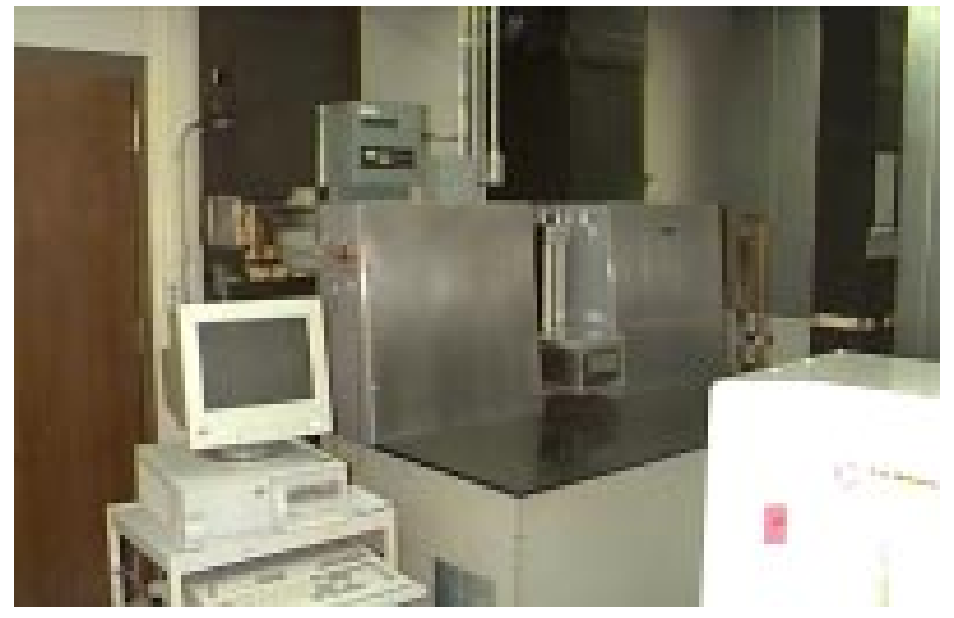

Figure 3. Computer controls were added to the laboratory forced air system.

Table 1 summarizes five elements of the indoor climate that are actively controlled by the refurbished forced air system. For one example, total air flow is controlled by the variable speed fan. A differential static pressure sensor, whose two probes are located before and after the fan, provides feedback on the actual air flow. Air flow in cubic feet per minute can be determined from fan differential static pressure by referencing the fan's performance curve. As a second example, static pressure inside the environmental chamber is controlled by the exhaust damper. Many buildings maintain a slight positive static pressure to minimize energy losses/gains due to infiltration. The differential static pressure sensor, which has one probe inside the environmental chamber and a second probe outdoors, provides the feedback that opens or closes the exhaust damper as needed. 
Table 1. The forced air system controls five air quality parameters in the chamber.

\begin{tabular}{|c|c|c|}
\hline Parameter & Actuator & Sensor \\
\hline total air flow & fan speed & fan differential static pressure \\
\hline humidity & humidifier/cooling coil & chamber relative humidity \\
\hline temperature & cooling coil/heating coil & chamber temperature \\
\hline static pressure & exhaust damper & chamber differential static pressure \\
\hline air recirculation & mixed air damper & outdoor air temperature \\
\hline
\end{tabular}

\section{Enhanced Features of Building Automation}

One of the greatest benefits of installing building automation equipment is its ease of use. Rather than monitoring individual gages as on the old system, user friendly screens provide real time information on a single computer screen. Figure 4 is the graphic for the forced air system. Notice that all mechanical components, such as the fan or dampers, are included in the sketch. Temperatures, pressures, and humidity readings are displayed in relation to their actual position. For example, Figure 4 locates the outdoor air temperature "47.2 F OAT" prior to the air handler. The supply air temperature "74.1 F DT" is located after the humidifier coil and before the environmental chamber.

Building automation equipment offers a wide range of enhanced features that are beyond the capabilities of older HVAC control systems. In terms of energy conservation, one of the most powerful features is the ability to schedule equipment operation. Turning off an air handler at night, when it may not be needed, can lead to tremendous energy savings. Another useful feature is the ability to view sensor inputs over periods of time. For example, graphs that display outdoor and indoor temperature over a period of hours or days are easy to generate and can be extremely helpful for troubleshooting control problems.

\section{Impact on Teaching and Learning}

As discussed earlier, building automation dramatically improved the performance of laboratory HVAC equipment by fine tuning system control and adding many convenient features. However, the positive impact on teaching and learning was even more significant. The most obvious and important benefit came from exposing MET students to state-of-the-art control technology. If MET programs are to fulfill their mission of delivering students who are prepared to "hit the ground running", it is imperative that laboratory equipment reflect what exists in the real world. Students in an MET "Air Conditioning and Refrigeration" elective will benefit from exposure to the building automation equipment that they will encounter during their careers. 


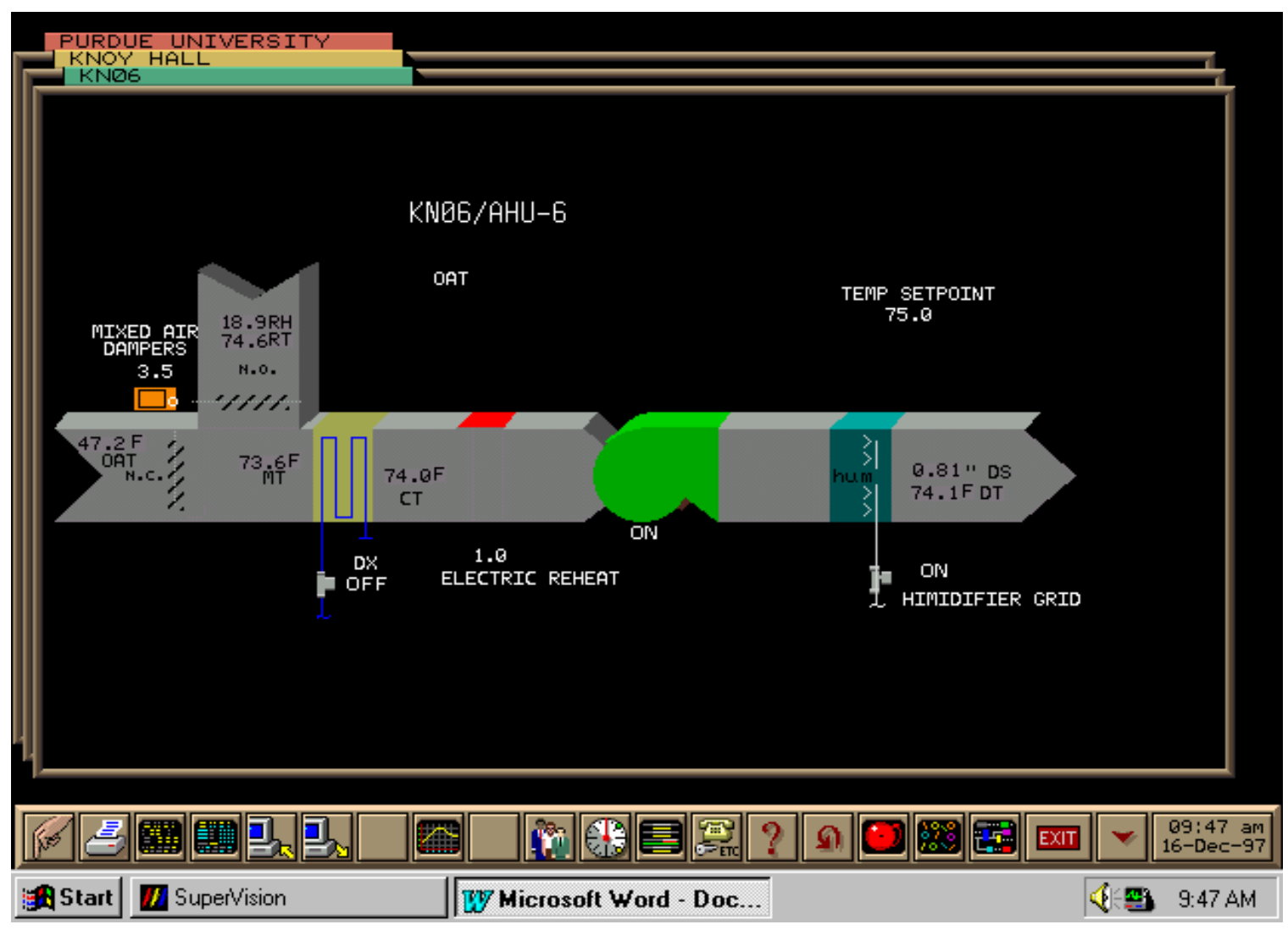

Figure 4. The user interface presents system information in a graphic format.

\section{Acknowledgement}

Automated Logic Corporation of Kennesaw, Georgia was the generous donor for most of the building automation equipment. This project would not have been possible without their generous support.

\section{References}

1. Kreider, J.F. and A. Rabi, (1994). Heating and Cooling of Buildings, Design for Efficiency, Mcgraw-Hill, New York, NY, pp. 1-8.

2. Thumann, Albert, (1996). Plant Engineers and Managers Guide to Energy Conservation, Fairmont Press, Lilburn, GA, pp. 6-20.

3. Lisack, J.P. and K. Shell, (1993). “Manpower Tid-Bit 93-5”, Office of Manpower Studies, Purdue University School of Technology.

\section{Biographical Information}

WILLIAM J. HUTZEL

He is an Assistant Professor in the MET Department at Purdue University, where his areas of expertise include HVAC and Controls. He can be reached by phone at (765) 494-7528 or by email at wjhutzel@ tech.purdue.edu. 